\title{
Los textos discontinuos: una posibilidad didáctica para favorecer la interpretación *
}

\author{
María Cristina Casas Sánchez \\ Institución Educativa José Antonio Galán, Medellín, Colombia \\ wina2621@hotmail.com \\ Tatiana Martínez Rivera \\ Institución Educativa La Esperanza, Medellín, Colombia \\ tatiana047@gmail.com \\ Ana Catalina Tamayo Duque \\ Institución Educativa José Antonio Galán, Medellín, Colombia \\ anacatalinatd101@gmail.com \\ Gloria Amparo Villa Acevedo \\ Institución Educativa San Antonio de Prado, San Antonio de Prado, Medellín \\ lagava2000@hotmail.com
}

\section{RESUMEN}

Este artículo es el resultado de la investigación realizada en las instituciones educativas públicas de Medellín: José Antonio Galán, La Esperanza y San Antonio de Prado. El objetivo fue explorar las posibilidades del uso de textos discontinuos como medio didáctico para fortalecer la interpretación en los estudiantes de grados $4 .^{\circ}$ y $5 .{ }^{\circ}$. La investigación fue de tipo cualitativo con un enfoque de investigación acción educativa, en la cual se implementaron seis situaciones de aprendizaje diseñadas a partir de algunos textos discontinuos de mayor circulación social que permitieron fortalecer procesos de comprensión e interpretación textual. El uso de los textos discontinuos representa un elemento diferenciador, ya que al ser poco abordados en las prácticas de aula, muestran una alternativa distinta de lectura más acorde con el tipo de textos que circulan en la actualidad, fortaleciendo de esta manera procesos interpretativos que llevaron al estudiante a asumir una postura de análisis, crítica y reflexión sobre asuntos que hacían parte de su cotidianidad y se referían a su entorno social, logrando vincular a la escuela los saberes extraescolares. Finalizado el proceso de análisis, se destacan hallazgos en torno a procesos de relectura, lectura autónoma, capacidad interpretativa sobre elementos textuales y paratextuales, aprendizaje colaborativo, identificación de información relevante, correlación entre texto y contexto y creación de nuevos textos a partir de ideas o formatos preestablecidos, hallazgos que permitieron concluir que se hace necesaria no solo la vinculación a los procesos de lectura diversas tipologías y formatos textuales, sino la enseñanza de estrategias que le permitan al estudiante mejorar su interpretación, y que la escuela se debe dar a la tarea de llevar al aula textos que tengan sentido para el estudiante y que correspondan al uso social de la lectura.

Palabras clave: interpretación; texto discontinuo; lectura en contexto.

Cómo citar: Casa Sánchez, M. C., Martínez Rivera, T., Tamayo Duque, A. C. y Villa Acevedo, G. A. (2018). Los textos discontinuos: una posibilidad didáctica para favorecer la interpretación. Ciencias Sociales y Educación, 7(14), 85-107. DOI: https://doi.org/10.22395/csye.v7n14a5

Recibido: 13 de agosto de 2018.

Aprobado: 10 de diciembre de 2018. 


\section{The Discontinuous Texts: a Didactical Possibility for Encouraging Interpretation}

\section{ABSTRACT}

This article is the result of research conducted are three public schools in Medellín: José Antonio Galán, La Esperanza y San Antonio de Prado. The main objective was exploring the possibilities for the use of discontinuous texts a didactical medium for encouraging interpretation in students from 4th and 5th grade. The method employed for the research was of a qualitative kind with a focus on learning situations designed from some discontinuous text with a greater social circulation that allowed the strengthening of comprehension and textual interpretation processes. The use of discontinuous texts presents a differentiating element given that these kind of texts, poorly used in class, are a reading alternative in conformity with the kind of texts of greater circulations nowadays and resulted in the strengthening of interpretative processes that lead students to assuming a critical, reflective and analytical attitude towards matters of their everyday life and its immediate social environment, thus resulting in a link of non-scholar knowledge in the school context. At the end of the analysis, certain findings are highlighted as the ones surrounding processes such as autonomous reading, re-reading, interpretative abilities with textual and paratextual elements, collaborative learning, detection of relevant information, correlation between text and context and creation of new texts from pre-established ideas or formats; findings that allows the research to conclude that the link between diverse typologies and text formats is necessary alongside the teaching of different strategies that allow the student the improving off its interpretation abilities and that school must undertake the inclusion of text with meaning for the student and with correspondence with the social use of reading.

Keywords: interpretation; discontinuous; reading in context.

\section{Os textos descontínuos: uma possibilidade diddática para favorecer a interpretação}

\section{RESUMO}

Este artigo é resultado da pesquisa realizada nas instituições educativas públicas de Medellín (Colômbia): José Antonio Galán, La Esperanza e San Antonio de Prado. O objetivo foi explorar as possibilidades do uso de textos descontínuos como meio didático para fortalecer a interpretação nos estudantes dos $4^{\circ}$ e $5^{\circ}$ anos. Esta pesquisa foi de tipo qualitativo, com uma abordagem de pesquisa-ação educativa, na qual foram implantadas seis situações de aprendizagem desenhadas a partir de alguns textos descontínuos de maior circulação social que permitiram fortalecer processos de compreensão e interpretação textual. O uso dos textos descontínuos representa um elemento diferenciador, já que, ao serem pouco abordados nas práticas de sala de aula, mostram uma alternativa diferente de leitura mais coerente com os gêneros textuais que circulam na atualidade, fortalecendo, dessa maneira, processos interpretativos que levam o estudante a assumir um posicionamento de análise, crítica e reflexão sobre assuntos que fazem parte de seu cotidiano e se referem a seu contexto social, conseguindo vincular os saberes extraescolares à escola. Finalizado o processo de análise, são destacados os achados sobre os processos de releitura, leitura autônoma, capacidade interpretativa sobre elementos textuais e paratextuais, aprendizagem colaborativa, identificação de informação relevante, correlação entre texto e contexto e criação de novos textos a partir de ideias ou formatos preestabelecidos, achados que permitiram concluir que é necessário vincular, aos processos de leitura, não somente diversos tipos e gêneros textuais, mas também o ensino de estratégias que possibilitem ao estudante melhorar sua interpretação, e que a escola deve levar à sala de aula textos que tenham sentido para o estudante e que correspondam ao uso social da leitura.

Palavras-chave: interpretação; texto descontínuo; leitura em contexto. 


\section{Introducción}

A nivel nacional, durante los últimos años, ha surgido un interés particular por mejorar los procesos de comprensión e interpretación lectora, lo que ha llevado a que la escuela se piense sobre la posibilidad de generar procesos en el aula que les permitan a los estudiantes enfrentarse a un texto mediante la enseñanza de estrategias que les faciliten destacar elementos que corresponden a los distintos niveles de comprensión. Sin embargo, los procesos de crítica y reflexión aún siguen siendo un punto álgido, lo cual se corrobora en los resultados obtenidos por las instituciones educativas del país en las diferentes pruebas de medición interna y externa.

Un eje fundamental es la interpretación en la escuela, debido a que la experiencia, la observación y algunas teorías confirman que en los procesos educativos no se enseña a interpretar. Aunque en las directrices del Ministerio de Educación Nacional (MEN) se hable de su importancia, las prácticas de lectura en el aula van en otro sentido y se han caracterizado por ser un ejercicio que se hace con el fin de dar cuenta de lo que dice en el texto en su sentido literal, no hay espacio para las discusiones sobre lo que acontece en las sociedades, no se generan vínculos entre escuela y contexto, en resumidas cuentas, no se lee para la vida, aspecto que sí está presente en los procesos de interpretación.

El concepto de interpretación se aborda desde los planteamientos de Colomer (1997), Gadamer (1993), Solé (1987), Lomas (2003) y Eco (1992), quienes coinciden en que es una posibilidad que tienen los estudiantes para identificar elementos que posee el texto en cada una de sus estructuras, pero yendo más allá de la comprensión para relacionarlo a una situación específica según su intención, su relación con lo que lo circunda y el contexto. De ahí que se haga necesario fortalecer, desde la escuela, los procesos de interpretación para la formación de seres críticos, analíticos, participativos y transformadores, capaces de trascender el texto escrito a una realidad inmediata, además de intercambiar puntos de vista, opiniones, llegar acuerdos y construir nuevos conocimientos.

Si bien existen investigaciones que tuvieron el mismo interés sobre los procesos que desarrolla la escuela en torno a la interpretación lectora de los estudiantes, se pudo identificar que la mayoría se centran en los procesos de comprensión o interpretación, pero desde los textos narrativos en formato continuo (Rojas, 2013), solo unas cuantas abordan la imagen, las historietas o los infogramas como medio para fortalecer la interpretación en los estudiantes (Salazar y Jaramillo, 2017), (Reyes y Mendoza, 2013), (Cervantes, Rivera y Varela, 2014), (Pineda 2011), (Narváez, 2016). Con respecto al uso de los textos discontinuos, se encontraron algunos trabajos en Perú que, aunque los nombran, no hacen su vinculación directa con la interpretación. Sin embargo, resaltan 
el hecho de que se está promoviendo el interés por involucrar en los procesos escolares otras formas de concebir la lectura más acorde con las exigencias del mundo actual, en las que se les posibilite a las nuevas generaciones medios, formas y recursos distintos para interactuar e intentar comprender e interpretar su realidad (Arriaga y Fernández, 2012; Chiclayo y Reyes, 2015).

Teniendo en cuenta que los lineamientos que regulan y orientan los procesos de enseñanza de la lectura, en nuestro país (MEN, 2007), dan diversas alternativas para que el maestro piense su práctica más allá del uso de textos en un mismo formato y de una misma tipología, es claro que aún no se ha hecho lo suficiente por llevar al aula los saberes extraescolares que le den sentido a la lectura y conlleven a mejorar dichos procesos de interpretación. De tal manera que los textos discontinuos se convierten en el medio que favorece dichos procesos al ser un formato no solo llamativo para el estudiante por sus características de diseño, sino porque le ofrece la posibilidad de generar distintas formas de abordarlo, son de alta circulación social y hacen parte de su cotidianidad al tenerlos visibles en espacios sociales.

La investigación, de índole cuantitativa, se llevó a cabo durante los años 2017 y 2018 en las instituciones educativas José Antonio Galán, La Esperanza y San Antonio de Prado de la ciudad de Medellín; el propósito fue explorar las posibilidades del uso de textos discontinuos como medio didáctico para fortalecer la interpretación en los estudiantes de grados $4^{\circ}$ y $5^{\circ}$. Esto se desarrolló usando una serie de situaciones de aprendizaje basadas en el uso de textos discontinuos de mayor circulación social y de las observaciones a los estudiantes y docentes, a través del uso del diario de campo y fichas de contenido.

\section{Metodología}

\section{Diseño}

El trabajo se enmarcó en un enfoque cualitativo, puesto que se pretende conocer y analizar realidades sociales mediante las experiencias e interacciones de quienes las protagonizan. Se busca observar, analizar y comprender las interpretaciones realizadas por los estudiantes sobre ciertos acontecimientos sociales a los que tienen acceso. La estrategia utilizada se centró en la investigación acción educativa, la cual permitió a las docentes asumir una postura de investigadoras y objetos de estudio a la vez, realizando reflexiones constantes sobre su práctica y buscando alternativas para transformarla según las exigencias del medio.

\section{Población y muestra}

La población objeto de estudio fue estudiantes de los grados $4 .^{\circ}$ y $5 .^{\circ}$ de las instituciones educativas José Antonio Galán, La Esperanza y San Antonio 
de Prado pertenecientes a la Secretaría de Educación del municipio de Medellín. Se tiene como muestra un grupo por institución con las siguientes características:

La institución educativa José Antonio Galán se encuentra ubicada en la comuna 3, barrio Manrique La Salle. El sector está estratificado principalmente en los niveles socioeconómicos 1,2 y 3. De dicha institución se eligieron como muestra los grupos 4.2 y 5.2. El grupo 5.2 está conformado por 32 estudiantes; 10 niñas y 22 niños, con edades que oscilan entre los 9 y los 13 años. El grupo 4.2 está conformado por 36 estudiantes; 24 niños y 12 niñas, con edades entre los 4 y 12 años.

Por su parte, la institución educativa La Esperanza se encuentra ubicada en la comuna 5, barrio Castilla, donde predominan, a nivel socioeconómico, los estratos 2 y 3 . El grupo elegido como muestra fue 5.3 conformado por 26 estudiantes de los cuales 11 son niñas y 15 niños, con edades entre los 10 y 13 años.

Finalmente, la institución San Antonio de prado se encuentra ubicada en la comuna 80 en el corregimiento que lleva su mismo nombre. La muestra se enfocó en el grupo 4.5 integrado por 38 estudiantes, 18 niñas y 20 niños con edades entre 9 y 13 años, quienes habitan tanto en el sector urbano como en el rural.

Un factor común que caracteriza la población y la muestra se relaciona con el desarrollo de las habilidades comunicativas en las que se evidencian falencias respecto a los procesos de comprensión e interpretación, en los niveles inferencial y crítico, lo que se hace visible en los resultados de pruebas estandarizadas (Saber, Olimpiadas del Conocimiento, Supérate con el Saber, Aprendamos) y los desempeños y procesos evaluativos constantes dentro las instituciones educativas.

\section{Consideraciones éticas}

Las autoras obtuvieron las firmas de los consentimientos informados de los padres de familia o acudientes de los estudiantes que participaron en esta investigación, a través de una reunión en la cual se les explicó a los responsables que los estudiantes serían partícipes de una entrevista y de una actividad de observación participativa, y que en el aula de clase se les aplicarían las situaciones de aprendizaje diseñadas, todo esto con el fin de recolectar la información que permitió obtener hallazgos y análisis de esta investigación. Además, se firmó otro consentimiento en el que los padres o acudientes autorizaron el uso de las imágenes y fotografías de las estudiantes con fines académicos como apoyo a los datos y hallazgos obtenidos en esta investigación. 


\section{Resultados}

\section{Recolección de datos}

Para la recolección de datos se utilizaron las técnicas de entrevista y observación. A continuación, se detallan.

\section{Entrevista}

Se realizó una entrevista semiestructurada a doce docentes de básica primaria, (tres de la I. E. la Esperanza sede los Comuneros; tres de la I. E. San Antonio de Prado, sede Carlos Betancur Betancur y seis de las I. E José Antonio Galán) y 16 estudiantes (cuatro de la I. E la Esperanza del grado 5, Sede los Comuneros; cuatro de la I. E San Antonio de Prado, del grado 4, sede Carlos Betancur Betancur y ocho de la I. E. José Antonio Galán, cuatro estudiantes de 5 y cuatro estudiantes de 4, seleccionados sin ningún criterio específico, los estudiantes lo hicieron por gusto y motivación propia).

En cuanto a las docentes, la selección se realizó de manera aleatoria, procurando la participación de diferentes grados de la básica primaria y de distintas áreas. El objetivo de dicha entrevista fue indagar sobre prácticas, experiencias y concepciones de los textos discontinuos en el aula y se diseñaron cuatro categorías: 1) Concepciones sobre los textos discontinuos; 2) Utilidad didáctica de los textos discontinuos; 3) Prácticas de aula con el texto discontinuo y 4) Razones de uso de este texto en el aula.

\section{Observación}

Durante el proceso investigativo, se realizó un ejercicio de observación participante en las mismas instituciones educativas, con algunas de las docentes que participaron en la entrevista, y cuyas áreas de desempeño son las de lengua castellana, sociales, inglés y matemáticas. Esto con el fin de analizar diferentes situaciones presentadas antes de la implementación de la propuesta, lo cual permitió visualizar el usos de los textos discontinuos en una situación de aula, además de la intención pedagógica con la que las docentes los presentaron y cómo los estudiantes interactuaron con ellos, y si se identificó el procesos de interpretación desde su uso, lo que posibilitó hacer un contraste a partir de lo encontrado en las entrevistas y brindó elementos para diseñar las situaciones de aprendizaje que se utilizaron.

\section{Análisis de los datos}

La propuesta de intervención diseñada en el proceso investigativo estuvo orientada bajo los parámetros de la estrategia Situación de aprendizaje, la cual 
permite una participación activa de docentes y estudiantes en torno a una temática particular que tiene como finalidad generar aprendizajes significativos y contextualizados. Para ello se toma como referencia el documento presentado por el Ministerio de Educación de Guatemala (2013) en el texto Situaciones de aprendizaje: pautas metodológicas para el desarrollo de competencias en el aula, en el cual definen que las situaciones de aprendizaje

Son momentos, espacios y ambientes organizados por el docente, en los que se ejecuta una serie de actividades de aprendizaje-evaluación-enseñanza, que estimulan la construcción de aprendizajes significativos y propician el desarrollo de competencias en los estudiantes, mediante la resolución de problemas simulados o reales de la vida cotidiana (p. 5).

En este sentido, lo que se pretende es permitir que los estudiantes desarrollen una serie de actividades de aula basadas en el uso de textos discontinuos con miras a fortalecer o mejorar los procesos de interpretación desde la capacidad de relacionar contenidos escolares con situaciones reales de sus contextos.

Se retomó esta estrategia por las posibilidades didácticas en las que pueden jugar los participantes, donde el docente "es quien diseña, planifica y desarrolla situaciones de aprendizaje interesantes, estimulantes y significativas para los estudiantes, de acuerdo con el curriculum" (p. 6) lo que significa que tendrá como rol no solo el diseño y creación de la situación, sino que le permite en el transcurso de la misma, ir direccionando los procesos, a las necesidades de la población y de la investigación como tal.

Por su parte, el estudiante tiene como función la participación activa dentro de su proceso de aprendizaje, valiéndose de la experiencia previa en su contexto y el aprendizaje colaborativo, que le permita construir nuevos conocimientos y asumir posturas críticas y reflexivas que lleven a la transformación de situaciones reales "es creativo, curioso e investigador, acepta desafíos, sabe trabajar en equipos colaborativos y es un participante espontáneo y diligente en la construcción individual y grupal del conocimiento" (p. 6).

Para el desarrollo de la situación de aprendizaje se tuvieron en cuenta tres fases, que dinamizan diferentes momentos de la intervención, cada uno con un propósito establecido.

Fase Inicial: es el punto de partida de la situación de aprendizaje, se busca motivar y generar interés en los estudiantes, para el desarrollo de la misma, en ella se plantea un desafío "reto o dificultad para motivar al estudiante, cuya solución permitirá nuevos aprendizajes, está basado en la o las competencias esperadas" (p. 11) y unos conocimientos previos, que son discutidos o mediados por las docentes investigadoras desde unas preguntas. 
Fase intermedia: es el centro de la situación de aprendizaje en donde se plantean una serie de retos o actividades enfocadas al fortalecimiento de la interpretación, a partir de la lectura de un texto discontinuo específico, teniendo en cuenta que parten del contexto del estudiante y promueven el aprendizaje colaborativo, esta fase finaliza con la puesta en común de la solución de los retos planteados.

Fase Final: es el cierre de la situación donde se retoman los resultados anteriores y se propone, generalmente, una producción grupal o individual que dé cuenta de los saberes o aprendizajes adquiridos en el proceso de interpretación del texto discontinuo llevado al aula.

Finalmente, la situación de aprendizaje es evaluada por los estudiantes a través de una rúbrica que tiene como finalidad valorar las percepciones, motivaciones, pertinencias del trabajo desarrollado, lo cual es el punto de partida para las siguientes situaciones de aprendizajes.

Lo anterior se evidencia en la figura 1.

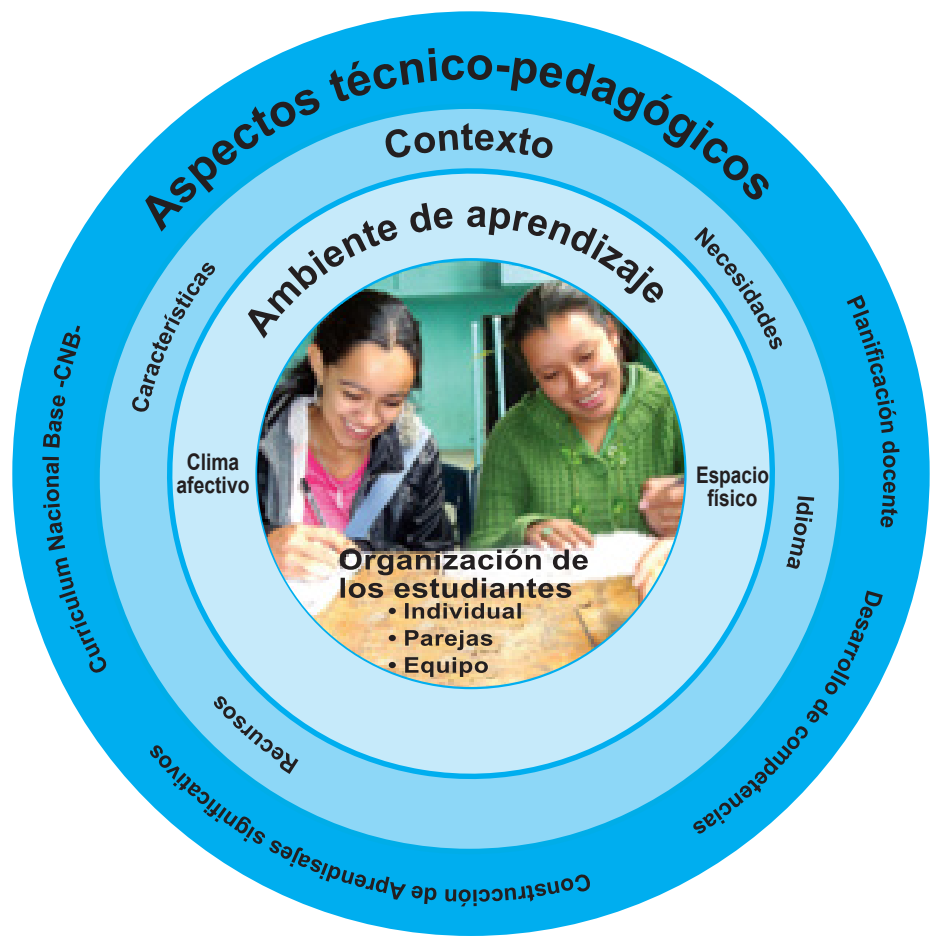

Figura 1. Fases dinamizadoras de una situación de aprendizaje.

Fuente: Ministerio de Educación de Guatemala (2013). 
Las situaciones de aprendizaje diseñadas se registraron en el diario de campo que es el registro acumulativo de todo lo que acontece durante el desarrollo de la investigación y, posteriormente, se analizaron las entrevistas, observaciones y los registros de los diarios de campo diligenciándolos en las fichas de contenido que fueron diseñadas por las investigadoras para tal fin. El sistema de fichas permite ordenar por categorías de análisis, confrontar, validar y cruzar datos, ubicar vacíos de información y complementarla permanentemente. Las categorías que se trabajaron en ellas fueron: lectura en contexto, texto discontinuo, interpretación y comprensión.

A continuación, se describen las situaciones de aprendizaje diseñadas para la ejecución de este trabajo (tabla 1).

Tabla 1. Situaciones de aprendizaje diseñadas e implementadas en la investigación

Situación de
aprendizaje

La situación exploratoria se dinamizó con el mapa del sistema integrado de transporte del Valle de Aburrá (Sitva). En la fase inicial se propuso armar un rompecabezas que contenía la imagen del mapa de este sistema de transporte, el cual debía armarse en un tiempo determinado y por equipos, apuntando así al trabajo colaborativo y proponiendo el desafío y los El mapa conocimientos previos a partir de preguntas relacionadas con la imagen.

En la segunda fase se planteó una serie de preguntas retomando los diferentes trayectos del Sitva y aspectos de interés para las personas que lo utilizan. En la fase final se propuso armar un mapa conceptual sobre este medio de transporte, integrando los diferentes servicios con los que cuenta y el reconocimiento que tiene a nivel de ciudad.

En las tres fases de esta situación de aprendizaje se trazó como objetivo aprender a leer e interpretar cuentas de servicios públicos, desde el análisis de los gráficos que allí se presentan.

Familiarizarse con la cuenta, observarla, detallar los aspectos que esta nos muestra y saber la empresa que presta los servicios que allí se relaciona fue la fase de la exploración. En la fase de la intervención se explicó, de manera detallada mediante una presentación en Power Point, don-

La cuenta de de se muestran los gráficos de cada uno de los servicios con los que se servicios cuenta en la vivienda, la lectura de los mismos en términos de consumo y de economía; seguidamente se trabajaron unas preguntas de selección múltiple con única respuesta, las cuales apuntan a los niveles de interpretación (literal, inferencial e intertextual).

Por último, se realizó una comparación de dos cuentas de servicios (la trabajada en clase y la de la casa de cada estudiante), en cuanto a los niveles de consumo de cada una, realizando gráficos que den cuenta de las semejanzas o diferencias entre ambas. 


\section{Situación de aprendizaje \\ Descripción}

El propósito central -en las fases uno y dos de esta situación- es el análisis, la comprensión y la interpretación de la información proporcionada mediante este tipo de texto, para la fase tres, su objetivo es la creación de afiches atendiendo a una situación específica.

En la primera fase, los estudiantes tuvieron como reto descifrar el mensaje que acompaña el texto encontrando las letras faltantes. Con esto se

El afiche pretende fortalecer los niveles de observación, análisis y comprensión, a la vez que su motivación frente al trabajo.

En la siguiente fase, se les entregó a los estudiantes un afiche sobre un concurso a realizarse en el barrio, a partir de este se les hicieron preguntas abiertas y de selección múltiple, encaminadas a fortalecer sus niveles de comprensión e interpretación. Finalmente, se les pidió a los estudiantes imaginarse un posible evento a realizarse en su barrio o escuela y diseñar un afiche con el que inviten a la comunidad a participar en él.

Esta situación de aprendizaje tiene como objetivo reconocer las características de la historieta como medio de comunicación social. Inicialmente, los estudiantes respondieron unas preguntas que sirvieron para la activación de saberes previos. Seguido a esto, observaron un video claro, corto y explícito acerca de lo que es una historieta y posteriormente realizaron lecturas sobre la creación de algunas historietas famosas y tradicionales.

El reconocimiento de estas historietas y del diseño de las mismas permitirá a los estudiantes familiarizarse con el ejercicio que deberán realizar

La historieta al final de la situación de aprendizaje.

Durante la fase intermedia se formaron seis equipos, los cuales hicieron una corta lectura sobre qué es la historieta y la estructura de la misma; esto generó la formulación y solución de siete preguntas de selección múltiple con única respuesta dentro de las cuales hubo cuestionamientos de tipo literal, inferencial e intertextual. Como finalización o cierre se entregó a cada estudiante una historieta sin mensajes o textos. La idea principal de esta actividad fue que cada niño, de acuerdo a las imágenes que observó en las viñetas, pudiera construir un texto con coherencia, sentido e ilación.

El diseño de esta situación de aprendizaje se hizo con la intención de hacer uso de un recurso común en el espacio escolar, pero más con los grados del primer ciclo. Sin embargo, se planteó con el objetivo de favorecer los procesos de interpretación desde la multiplicidad de paisajes, formas y

El libro álbum elementos simbólicos que usa el autor del texto para contextualizar cada una de las miradas que dan los personajes de la historia a un simple paseo por el parque.

Se inició con un espacio de indagación e inferencia previa respecto a la carátula y los elementos que hay en ella, para continuar con la construcción grupal de la historia a partir de las imágenes entregadas aleatoriamente, 


\section{Situación de} aprendizaje

Descripción

las cuales correspondían al cuento. Esto permitió trabajar elementos sintácticos del texto además de ponerle un sentido e ilación a cada una las partes que se van uniendo. Esta producción se confrontó luego con la lectura del texto original a partir del cual se trabajaron una serie de preguntas desde la estrategia de aprendizaje colaborativo que llevó a indagar por la interpretación de los distintos elementos que propone el texto en su diseño gráfico.

Se finalizó con un espacio producción donde los equipos proponen una quinta voz en la historia, la cual es socializada ante los demás compañeros.

Con esta situación de aprendizaje se finalizó el proceso en el aula, la cual tuvo como objetivo reconocer la intencionalidad comunicativa de los textos discontinuos para la creación de infografías. Se inició con una fase de indagación y exploración de saberes previos donde los estudiantes diligenciaron una guía de observación sobre un infograma elegido de acuerdo a sus gustos e intereses y que respondieron a las percepciones que tienen respecto a la forma, diseño, intención, contenido, uso social del mis-

El infograma mo. Se socializó y se compartieron las opiniones por los grupos de trabajo.

Luego se continuó con la fase intermedia donde se mostró a los estudiantes las características de la infografía desde su forma y contenido y se propuso la construcción de un infograma a partir de la elección de unas temáticas dadas.

Se finalizó con la socialización de las creaciones, donde se dio cuenta de la apropiación sobre el diseño según los parámetros establecidos para la creación del mismo.

Fuente: elaboración propia

\section{Discusión de los resultados}

\section{Prácticas, experiencias y concepciones, de los textos discontinuos en el aula}

\section{Concepciones sobre los textos discontinuos}

Tanto estudiantes como docentes conocen poco el texto discontinuo, por lo cual fue necesario hacer una breve explicación y mostrar algunas imágenes que permitieran orientar el diálogo generado en la entrevista. Por su parte, los estudiantes hicieron una relación sobre este tipo de texto con los cuentos que se narran por medio de imágenes o dibujos: reconocen más los textos publicitarios (vender un producto, anunciar algo), imágenes que observan en lugares de acceso cotidiano; al igual que identifican los cómics y carteles, el texto también tiene una relación con los espacios que ellos visitan como parques, centros de salud y tiendas, entre otros. Esto se evidenció en respuestas de los estudiantes como: "los he visto donde la doctora con la curva de crecimiento, en el mapa 
del metro, en la cuenta de los servicios y a veces en la clínica. Sirven para uno guiarse y saber cosas".

Aunque los estudiantes no tenían conocimiento acerca de lo que es un texto discontinuo desde la teoría, al ver las imágenes mostradas por las docentes, lo relacionaron con su entorno y cotidianidad. De ahí que sea importante como lo dicen Mockus, Hernández, Granes, Charum y Castro en su texto Las fronteras de la escuela (1994) articular el conocimiento común con el conocimiento escolar.

Hacer más permeable la escuela a la cultura extraescolar y a la elaboración de la propia experiencia, lo cual implica debilitar las fronteras de la escuela abriéndola a los distintos juegos de lenguaje que circulan en la comunidad extraescolar a la vez que permite formas de comunicación y de conocimiento que han estado vedadas hasta ahora en la llamada cultura escolar (p. 368).

Las docentes, por su parte, lograron relacionar el texto discontinuo con los textos que contienen imágenes y que hacen parte del entorno escolar, más que de la cotidianidad del estudiante; es decir, su uso se restringe al apoyo didáctico para una clase en particular, a partir del uso de diagramas, mapas conceptuales o afiches sobre un tema puntual, entendiendo los textos discontinuos como organizadores gráficos que se utilizan para facilitar la explicación y la comprensión de una información. Esto se contrasta con lo encontrado en la investigación de Narváez (2016), donde la investigadora plantea la misma dificultad sobre el uso de textos discontinuos en el aula, que para su caso eran las infografías.

Contrastando las concepciones de los estudiantes con las de los docentes, es posible observar cómo el saber escolar se aleja de los saberes extraescolares, allí donde el maestro está en función de academizar la lectura sin valorar los recursos que ofrece el contexto del estudiante que también puede enriquecer ese proceso, teniendo más sentido para este y favoreciendo los procesos de comprensión e interpretación. Revisando los currículos de las instituciones educativas donde se lleva a cabo esta investigación, aparece como limitante la poca variedad de tipologías textuales para el desarrollo de las clases, en la mayoría de los casos se privilegia el texto en formato continuo y correspondiente al género narrativo, factor que ha sido preocupación también de otros estudios.

Hernández, citando a Pérez y Gómez (2007) menciona que "las enseñanzas de la vida y las costumbres del pasado no son suficientes para afrontar los desafíos del presente y las exigencias del futuro" (p. 1), asegura que las sociedades han cambiado y la escuela ha de cambiar con ellas y modificar su manera de formar a los futuros ciudadanos, para lo que se debe valer de la cantidad de tipologías textuales presente en las sociedades.

De igual manera, se encuentra ausente en los planes de estudio el uso del texto discontinuo como una posibilidad didáctica, aunque la revisión documental da cuenta de que el MEN ha estado en función de dinamizar procesos académicos 
orientados al uso e implementación de diferentes tipologías textuales, desde las directrices dadas en las matrices de aprendizaje, alineadas con los derechos básicos de aprendizaje en su segunda versión.

\section{Utilidad didáctica de los textos discontinuos}

En cuanto a la utilidad de este tipo de texto, las docentes piensan que su uso puede favorecer los procesos de aprendizaje y diversifica los de enseñanza; consideran importante su trabajo desde todas las áreas del conocimiento, aunque mencionan que áreas como matemáticas y lenguaje ofrecen mayores posibilidades de uso por los contenidos que desarrollan. "Aunque se puede aplicar en todas las áreas, considero que las más afines serían matemáticas y lengua castellana, porque permite leer, analizar e interpretar de forma rápida y fácil, puesto que no hay textos largos, lo que incita a leer sin generar apatía". Planteamiento que puede ser contrastado con el de Minervini (2005) donde se determinó la medida en que los gráficos informativos tenían impacto en la búsqueda y obtención del conocimiento y la forma en que las infografías se convirtieron en un recurso pedagógico para los jóvenes. Otro hallazgo fue sobre las prácticas en la clase de ciencias naturales, puesto que tuvieron mayor significado al utilizar infografías en el proceso de enseñanza y aprendizaje.

Con respecto a las ventajas y desventajas que los textos en este formato presentan, se hace visible que su vinculación al aula agrega un factor motivador, sirve como una estrategia para sintetizar información y para enseñar a localizar datos clave pero, a la vez, podrían presentar dificultades de comprensión e interpretación en los estudiantes al no estar familiarizados con ellos. Sin embargo, estos textos son contemplados como un recurso didáctico que apoya los procesos de conceptualización de un contenido curricular o para ampliar la información dada por el docente, más que como una posibilidad didáctica para favorecer procesos de lectura en contexto.

\section{Prácticas de aula con el texto discontinuo}

Respecto a las tipologías textuales que más predominan en las prácticas de aula, las docentes expresan que usan variedad, aunque hay coincidencia en que predomina el texto narrativo y que emplean las gráficas, los mapas o las tablas de frecuencia solo como una ayuda visual, es decir, que se le otorga valor a la imagen desde una mirada motivacional, por ser del agrado de los estudiantes, más que por los procesos que se puedan desarrollar a partir de ellas con respecto a la comprensión e interpretación de lectura. Esto se corrobora en las observaciones hechas a las prácticas de aula de algunas docentes en la medida que no hubo una intención clara sobre el uso del texto discontinuo ni se le atribuyó una función didáctica que conlleve a generar aprendizajes desde su lectura, solo se 
propuso por ser más llamativa; es decir no hubo un acercamiento por parte de la docente a su lectura, estructura, propósitos o componentes que pudieran dar lugar a posibles interpretaciones según el sentido que le diera cada estudiante.

En cuanto a los textos que los docentes implementan en el aula, los estudiantes mencionan que llevan los dos tipos de textos (continuos y discontinuos), mapas conceptuales, mentales y sinópticos, imágenes, muchos textos narrativos y expositivos, más que todo cuentos y fábulas, en cuanto al gusto por algún tipo de texto mencionan de forma paralela gusto por ambos, por una parte los continuos, por los cuentos, por la lectura que se realiza con estos y el trabajo constante en las clases; los discontinuos, por su parte, por las imágenes que tienen, los mapas conceptuales porque resumen la teoría, las tablas e infografías que aunque poco se trabajan les generan curiosidad y agrado. "Los continuos, porque ahí puedo comprender más y por medio de la imagen no sé muy bien lo que se está dando, o si está bien lo que yo veo o no".

Esta misma necesidad la plantea Narváez (2016), cuando en su investigación sobre el uso de la infografía para mejorar la interpretación hace un llamado a diversificar los textos que se llevan al aula para que se involucren elementos cotidianos para los estudiantes e imágenes que permiten nuevas formas de leer.

\section{Razones de uso del texto discontinuo en el aula}

Las docentes entrevistadas afirman que los textos discontinuos son poco usados en la escuela debido a su desconocimiento, lo que implica que se debe hacer un trabajo de selección de contenido, estructura y de la tipología discontinua que más posibilidades le puede ofrecer en el aula según el interés pedagógico que pretenda desarrollar, lo que no ocurre con el texto continuo que ya es conocido por el docente por su experiencia de años anteriores.

Por otra parte, el trabajo en el aula con el texto discontinuo conlleva a generar espacios de diálogo y discusión entre pares, lo que para algunos maestros puede ser visto como desorden, indisciplina o un factor de distracción que desvía la atención del estudiante a otros contenidos que no corresponden a su currículo, aunque no descartan la posibilidad didáctica de usar variedad de textos en el aula y así favorecer diferentes procesos pedagógicos.

\section{Situaciones de aprendizaje que fortalecen la interpretación}

\section{La interpretación y los textos discontinuos: una posibilidad didáctica para la lectura}

La comprensión e interpretación lectora representan una de las categorías centrales de la propuesta de investigación, se buscó favorecer estos procesos 
desde el uso de textos discontinuos como posibilidades didácticas. En las diferentes situaciones de aprendizaje fue evidente cómo a los estudiantes se les dificulta dar cuenta de elementos textuales que fueran más allá de la literalidad, generando conflictos cognitivos para la resolución de las preguntas que partían de convenciones o de elementos gráficos que contenían los textos.

Esta situación no solo ratificó la necesidad de llevar al aula propuestas lectoras distintas a las que, cotidianamente, se hacen con los textos continuos, sino que mostró el desconocimiento, por parte del estudiante, frente a la lectura de otras tipologías y formatos de textos en los que se requiere generar una relación distinta entre lector, texto y contexto. Se observó dificultad en este proceso: los estudiantes no se fijan en los detalles de la imagen y en cada uno de los elementos que contiene y la información que esto le brinda, por lo cual pocas veces se llegó a relacionar el contenido del texto con situaciones de su vida cotidiana.

Respecto a la habilidad lectora de los estudiantes, en las primeras situaciones de aprendizaje, se evidenciaron procesos de compresión más que de interpretación, siendo evidente que, al momento de resolver las preguntas, en los grupos de trabajo se llegaron a consensos claros en los enunciados de tipo literal pero cuando se enfrentaron a preguntas de tipo inferencial o crítico hubo ideas encontradas que impidieron, en algunos casos, elegir una de las opciones, por la misma dificultad de ubicar el texto o planteamiento en una situación cotidiana que implica salirse de la estructura del texto para lograr identificar su sentido e intención. Interpretar significa situar, como lo define Álvarez (1996):

Ubicar interpartes de un texto, es una actividad mucho más compleja que entender o comprender; pues, exige que el lector modifique su ubicación en un espacio sociocultural, por cuanto deberá introducirse, imaginariamente, en el ámbito del texto y moverse culturalmente dentro de él; además de escoger las partes o componentes del texto y jerarquizar lo que él considere, en dependencia de sus intereses, motivos u objetivos definidos por él. (p. 12)

La interpretación se fue logrando de manera paulatina en las situaciones de aprendizaje, observando avances en los desempeños de los estudiantes en cada uno de los enunciados correspondientes al nivel intertextual, al realizar comparaciones entre los momentos presentados; es decir el texto, el contexto, la situación particular presentada y el análisis de esta con otras más, permitiendo traspasar los límites de lo educativo a lo social, escenario en el cual los estudiantes, de una u otra forma, se vieron reflejados e inmersos en las situaciones.

En este sentido, se entiende que la interpretación no se limita solo a la relación entre lo que se lee y la intención del texto, sino que va más allá, pues 
la interacción entre texto, lector y contexto permite identificar elementos que trascienden al texto y obliga al lector a repensar el comportamiento de los demás, pero también lo llevan a reflexionar sobre sí mismo, su contexto y las dinámicas sociales que se desarrollan, creando así una posibilidad de transformación en sí mismo, como lo expone Lerner (2001):

Porque formar lectores autónomos significa, entre otras cosas, capacitar a los alumnos para decidir cuándo su interpretación es correcta y cuándo no lo es, para estar atentos a la coherencia del sentido que van construyendo y detectar posibles inconsistencias, para interrogar el texto buscando pistas que avalen tal o cual interpretación o que permitan determinar si una contradicción que han detectado se origina en el texto o en un error de interpretación producido por ellos mismos... Se trata entonces de brindar a los niños oportunidades de construir estrategias de autocontrol de la lectura (p. 149).

De esta forma, los estudiantes efectuaron un ejercicio de interpretación a partir de sus experiencias previas, para terminar reflexionando y transformando sus saberes desde su subjetividad y sus situaciones reales de comunicación.

Los textos discontinuos movilizaron en los estudiantes situaciones motivacionales intrínsecas y extrínsecas. El observar más imágenes que texto y entender que ellas también se leen y dan cuenta de una información generó, de una u otra manera, procesos de lectura interpretativa, al poder comparar cuáles desplazamientos se realizan de una estación a otra en el caso del mapa del Sitva; comparar consumos en la factura de servicios públicos y del impacto de estos en la economía familiar, la función social que tiene el afiche publicitario y sus implicaciones éticas frente a la mirada del consumidor, la historieta y sus posibilidades de expresar asuntos políticos y demás aspectos que permitan hacer una crítica social; el libro álbum al permitirles identificar elementos que tienen que ver con las emociones transmitidas y cómo la interpretación tienen que ver con las diferentes miradas que dan las personas a un mismo texto y a una misma situación, y el infograma con todas las posibilidades diversas que ofrecen los textos discontinuos para la enseñanza de contenidos escolares y el análisis de situaciones extraescolares.

Durante las situaciones, el texto discontinuo jugó un papel muy importante al movilizar procesos de comprensión e interpretación en los estudiantes; su manipulación se hizo cada vez más clara y específica, lograron identificar los propósitos, estructura, función comunicativa y uso social de cada texto, replantearon sus formas de lectura frente al texto, propiciando procesos de relectura autónoma, dándole una mirada distinta a textos en este formato, ya no como algo solo académico y de uso escolar, sino desde su uso cotidiano, que en diferentes lugares se pueden ver y que cumplen una función comunicativa. 


\section{La lectura en contexto: diálogo entre los saberes escolares y extraescolares}

La lectura en contexto fue otro de los intereses principales durante esta investigación, entendida como la que se hace con el fin de comprender e interpretar los sucesos que acontecen en la realidad. Este tipo de lectura le permite al estudiante poner en diálogo los saberes escolares con el mundo en el que habita y lo dotan de elementos que le facilitan su participación dentro de los contextos sociales.

Las situaciones de aprendizaje desarrolladas se convirtieron en un pretexto para trasladar esas prácticas de lectura a un entorno conocido por los estudiantes, generando mayor interés y motivación al sentirse parte de ese escenario y reconocerse dentro de él, a la par que se amplió el abanico de posibilidades respecto a los tipos de textos abordados en el aula. De igual manera, favoreció que las discusiones dentro de los grupos fueran más vivenciales y anecdóticas, los estudiantes participaron con mayor confianza y compartieron diferentes experiencias.

Lo que debe generar una lectura en contexto es que los estudiantes se apropien de su territorio, lo conozcan y sean miembros activos en él, que "aprendan a leer en forma crítica y se preparen para la vida académica, laboral, social y afectiva, considerando que la lectura no es solo un medio para acceder al conocimiento, sino una herramienta fundamental para vivir, pensar, aprender y disfrutar" (Ministerio de Educación de Chile, 2015, p. 4).

El contenido de los textos discontinuos, empleados en las diferentes situaciones de aprendizaje, estuvo enmarcado en circunstancias propias del contexto cercano de los estudiantes, y a partir de ellos se generaron una serie de discusiones que, aunque basadas en las experiencias extraescolares, las docentes direccionaron hacia procesos intertextuales de comprensión e interpretación, con el objetivo de profundizar en el sentido de algunas de las acciones que a diario se observan, tal como lo plantea Lerner (2001)

Leer es adentrarse en otros mundos posibles. Es indagar para comprenderla mejor, es distanciarse del texto y asumir una postura crítica frente a lo que se dice y lo que se quiere decir, es sacar carta de ciudadanía en el mundo de la cultura escrita. (p. 2)

Los hallazgos dejan ver cómo los saberes escolares y extraescolares sí pueden coexistir y dirigirse a unos mismos propósitos, contradiciendo algunas de las ideas que los docentes han tenido respecto a la enseñanza de la lectura en la escuela en el sentido que no es posible que escuela y sociedad dialoguen, pues se han creado barreras entre ambas, pensando que lo social no permea los aprendizajes escolares y que estos se enseñan desconociendo los que sucede 
fuera, descontextualizando así el proceso de enseñanza de la lectura sobre la realidad de los estudiantes al limitar esta habilidad como una condición necesaria para el contenido escolar, pero desconociendo, en muchos casos, el contexto en el que se desarrolla; es decir, se fragmenta la lectura, de modo tal que sea más fácil su enseñanza en contraste con que fuera presentada en su globalidad y las implicaciones que ello trae con respecto a los procesos de comprensión e interpretación. La enseñanza se aleja de la búsqueda por encontrarle sentido a la función social de la lectura, pues ello no es requisito para el aprendizaje ni hace parte de los objetivos trazados en los currículos, desconociendo así las múltiples posibilidades de aprender y de enseñar a leer.

Trascender en los procesos de aprendizaje, involucrando y reconociendo el contexto, permite que el estudiante demuestre más interés y establezca relaciones entre las experiencias propias y las escolares. El tener inmerso el contexto dentro de la aplicación de cada situación de aprendizaje, no solo acercó al estudiante a la lectura de textos discontinuos sino al reconocimiento de su función social, al poder relacionarlos con su cotidianidad, saliéndose de unos esquemas de trabajo con textos escolares cotidianos, e identificando dentro de sus hogares otras posibilidades de lectura, que permiten generar nuevos conocimientos y aplicar su aprendizaje a la resolución de problemas desde el ámbito escolar y familiar, correlacionar lo abordado en la escuela y su hogar y cómo esto puede ser útil para su actuar en sociedad.

\section{El aprendizaje colaborativo: aprender a interpretar juntos}

Las situaciones de aprendizaje implementadas arrojaron una posibilidad de aprendizaje colaborativo, pues se generaron espacios donde los estudiantes lograron compartir ideas, debatir sus posturas y sobre todo llegar a consensos, mediando los aprendizajes y procesos de comprensión e interpretación. Respecto a la posibilidad de aprender juntos y de manera individual al mismo tiempo, Collazos y Mendoza (2006) describen este proceso como la interdependencia positiva, que tiene que ver con la capacidad de colaborar en la realización de una tarea porque se es consciente que así se podrán alcanzar los objetivos propuestos.

El aprendizaje colaborativo no fue una categoría contemplada dentro del proceso inicial de la investigación, pero con la implementación de las situaciones de aprendizaje fue evidente cómo se transformó en una categoría emergente que posibilitó el desarrollo de cada una de las fases, dentro de las cuales los grupos de trabajo asumieron roles que los llevaron al alcance del objetivo propuesto; es decir, para los estudiantes fue más significativo el lograr procesos de comprensión e interpretación guiados por las capacidades y habilidades de 
otros compañeros, incluso más que a partir de las orientaciones ofrecidas por la docente.

El aprendizaje colaborativo como estrategia permite al estudiante trabajar conjuntamente, hacer que adquiera mayor confianza en sus propias opiniones para enfrentarse a los distintos retos cognitivos, es más abierto a opinar y a dar ideas, reconocer liderazgos, asumir distintos roles, ver el error como parte del proceso de aprendizaje, asumir una actitud de escucha, respeto y llegar a consensos.

Si bien el texto discontinuo no exige para su implementación el aprendizaje colaborativo, durante las situaciones fue posible establecer cómo esta estrategia permitió que los estudiantes usarán la imagen (texto presentado) a favor de la interpretación, desde la posibilidad de tomar elementos del texto y ponerlos a discusión con sus compañeros, en la medida que este formato no exige que se haga una lectura de tipo lineal, dándoles la posibilidad de retomar elementos de su interés en la globalidad del texto, para luego converger las situaciones interpretativas de cada uno y ajustar el sentido global del texto según la situación presentada; es decir, el tener distintas percepciones sobre una misma situación y ponerlas en común, da la posibilidad de superar los límites de la comprensión al identificarse elementos no percibidos por el lector, pero sí por uno de sus pares, correlacionados con el contexto, generando así nuevos aprendizajes.

En contraste con los resultados obtenidos, en las entrevistas a las docentes y en las posteriores observaciones a sus prácticas de aula, se plantearon las dificultades para la implementación de los textos discontinuos, y se expresaba con testimonios como: "la desventaja es que los estudiantes no están muy habituados a trabajar este tipo de texto y se les hace difícil al principio interpretar la información o trabajar con ellos", opuesto a lo observado en el desarrollo de las situaciones de aprendizaje como el mapa del metro, la cuenta de los servicios o el infograma, donde se apreciaron altos niveles de motivación y participación con este tipo de textos, así como la capacidad de abstracción de información, relación del texto con el contexto y procesos de relectura espontánea.

\section{Conclusiones}

Los textos en formato discontinuo fortalecen los procesos de interpretación, en la medida que el estudiante da cuenta de un mayor nivel de análisis sobre elementos del texto que comúnmente se le dificultan a partir de un texto continuo, debido a que la tipología usada presenta características flexibles frente al proceso lector, en el cual el estudiante puede iniciar la lectura desde diferentes partes del texto y se presentan elementos gráficos que apoyan y explican el contenido, se construyen saberes entre pares donde se validen o 
refuten opiniones, se facilitan procesos de relectura que llevan a identificar de forma rápida información clave, se establecen vínculos con las problemáticas del exterior, pues cada texto tiene una función social que resulta familiar para el estudiante. Este tipo de texto no jerarquiza la información ni esquematiza contenido, lo cual favorece una lectura global, abarcando más información que nutre la comprensión y la interpretación.

El trabajo con los textos discontinuos contribuye a que el estudiante asuma el proceso de lectura con una mirada diferente al entorno escolar, donde sus propios saberes entran a dialogar con los planteamientos del texto para generar procesos de interpretación. A su vez, le otorga autonomía al lector; es él mismo quien pasa a determinar qué elementos son válidos o no de acuerdo con sus interpretaciones, ya que no se trata simplemente de asumir posturas frente al texto, sino estar en sintonía con lo que se lee y con la intención comunicativa.

El poco uso y manejo que los docentes, en su práctica, le dan a la lectura de textos discontinuos en los procesos escolares, hace que los estudiantes no los identifiquen como elementos que les permita debatir saberes y construir conocimiento, por lo tanto, se puede convertir en un factor de distracción que genera situaciones poco favorecedoras de aprendizaje desde las actitudes que puedan asumir, de ahí que sea tarea del docente brindar orientaciones claras sobre la forma de leer estos textos, sus estrategias para la interpretación, dar nociones sobre su estructura y elementos que lo conforman y a situarlo en el espacio escolar que lleva finalmente a que el estudiante le otorgue un papel importante para encontrar el sentido comunicativo y su función social.

Al utilizar las situaciones de aprendizaje, se articulan los procesos escolares con los extraescolares ya que al involucrar en cada una de ellas textos de circulación social y que hacen parte de la cotidianidad del estudiante, se logra que los procesos de pensamiento se movilicen a favor de la interpretación como un nivel superior a los procesos de comprensión lectora a los que llegan los estudiantes en los grados escolares con los que se trabajó. En este sentido, se hace pertinente que la escuela, como escenario para la formación de sujetos críticos y reflexivos, vincule, a los procesos de lectura, el uso de textos de alta circulación social en los que el estudiante logre ver reflejada su realidad y se apropie de elementos que le permitan acercarse a procesos de interpretación que, no necesariamente, respondan a un contenido escolar lejano de sus intereses, sino que logren vincularlos con su entorno.

Los procesos metacognitivos evidenciados durante los diferentes encuentros llevaron a que los estudiantes reconocieran, desde su individualidad, la manera de aprender y comprender cómo dar solución a cada una de las actividades, valorando la importancia del texto discontinuo desde su estructura, contenido 
y propósito, a la par que se modifican y enriquecen opiniones -desde el diálogo y el debate- que surgen dentro de los espacios de disertación.

Para los procesos de comprensión e interpretación, es importante llevar a los estudiantes a realizar estrategias metacognitivas que le permitan valorar su proceso de lectura y detectar posibles errores. En la medida en que se es consciente de cómo opera el propio pensamiento, se logran generar acciones de planificación y organización del hacer cognitivo, fortaleciendo así el nivel de desempeño. Así, cuando los estudiantes alcanzan un nivel de autorregulación y conciencia sobre el proceso de lectura, logran desarrollar competencias metacognitivas, siendo posible reconocer las dificultades que tienen para acercarse a un texto específico, identificar su estructura, intención o sentido global, lo cual conduce a realizar acciones de voluntarias de chequeo, verificación de información y relectura, sin la necesidad de ser orientados por el docente.

$\mathrm{El}$ aprendizaje colaborativo genera mayores posibilidades de procesos interpretativos en la medida que los estudiantes discuten sus ideas, logrando llegar a consensos sobre cuál se acomodaba más a lo que se indagaba sin perder el sentido del texto. Si bien hay tantas interpretaciones como lectores, es cierto que estas ideas no deben estar alejadas del propósito comunicativo del texto, y fue precisamente a lo que contribuyeron los espacios de diálogo que se generaron en cada una de las situaciones llevadas al aula.

\section{Agradecimientos}

Este artículo presenta los resultados del trabajo de investigación denominado El texto discontinuo: posibilidades didácticas del para favorecer la interpretación, realizado durante la Maestría en Educación, en la Línea Didáctica de la lectura y la escritura de la Universidad de Medellín. La investigación fue orientada y asesorada por la profesora Luz Adriana Restrepo Calderón, magíster en Docencia Lenguaje y Educación de la Universidad de Antioquia.

\section{Referencias}

Álvarez, L. (1996). La lectura: ¿Pasividad o dinamismo?. Educación, (89). 59-66. Recuperado de https:// www.redalyc.org/pdf/1813/181321553007.pdf

Arriaga, L. y Fernández K. (2012). Taller: mejorando mi creatividad en el desarrollo de las habilidades de producción de textos discontinuos en los estudiantes de $5^{\circ}$ grado de primaria de la I.E Salaverry del distrito de Salaverry -Trujillo (Tesis de Maestría). Universidad Cesar Vallejo, Trujillo, Perú.

Cervantes, M., Rivera, M. y Varela, L. (2014). La historieta como potenciadora de la capacidad interpretativa: una propuesta pedagógica que vincula texto y contexto en los estudiantes de básica secundaria del nocturno Manuel Uribe Ángel (MUA) de Envigado. (Tesis de pregrado). Universidad de Antioquia, Seccional Envigado. Colombia. 
Colomer, T. (1997). La enseñanza y el aprendizaje de la comprensión lectora. Recuperado de http://www. ceip.edu.uy/IFS/documentos/2015/lengua/materiales/ColomerTeresaComprension.pdf

Collazos, C., y Mendoza, J. (2006). Cómo aprovechar el "aprendizaje colaborativo" en el aula. Educación y Educadores, 9(2), 61-76.

Chiclayo, M. y Reyes, L. (2016). Relación entre la competencia comunicativa de comprensión de textos continuos y la competencia comunicativa de producción de textos discontinuos en los alumnos del 3er grado del nivel primaria del C. E. E. "Rafael Narváez cadenillas" y de la I. E. n. 81014 Pedro M. (Tesis de pregrado). Universidad Nacional de Trujillo, Perú.

Eco, U. (1992). Los límites de la interpretación. Barcelona: Grupo Editorial España.

Fernández, T. (2012). La publicidad: ejemplo de actividades para primaria. En F. Guerra, R. García, N. González, P. Arellano y A. Castro (Coords.), Estilos de aprendizaje: investigaciones y experiencias (V Congreso Mundial de Estilos de Aprendizaje, Universidad de Cantabria) (pp.1-10). Santander: Universidad de Cantabria.

Gadamer, H. (1993). Verdad y método. Salamanca: Sígueme.

Lerner, D. (1998). Es posible leer en la escuela. Lectura y vida: revista latinoamericana de lectura. 17(1), $2-20$.

Lerner, D. (2001). Leer y escribir en la escuela: lo real, lo posible y lo necesario. Ciudad de México: Fondo de cultura económica.

Lomas, C. (2003). Leer para entender y transformar el mundo. Madrid: Santillana.

Minervini, M. (2005). La infografía como recurso didáctico. Revista Latina de Comunicación Social, 8(59), Recuperado de http://www.revistalatinacs.org/200506minervini.pdf

Ministerio de Educación Nacional. (2007). Investigación de los saberes pedagógicos. Bogotá: Ministerio de Educación Nacional.

Ministerio de Educación de Chile. (2015). La lectura, una práctica social que se inicia formalmente en la escuela. Recuperado de https://basica.mineduc.cl/la-lectura-una-practica-social-se-iniciaformalmente-la-escuela/

Ministerio de Educación. Sidecar. Ministerio de Educación de Guatemala. (2013). Situaciones de aprendizaje: pautas metodológicas para el desarrollo de competencias en el aula. Ciudad de Guatemala: Universidad del Valle de Guatemala.

Mockus, A., Hernández, C., Granes, J. Charum, J. y Castro, M. (1994). Las fronteras de la escuela. Educación y Pedagogía, (12-13), 368-381. Recuperado de http://aprendeenlinea.udea.edu.co/revistas/ index.php/revistaeyp/article/view/6231/5747

Narváez, S. (2016). El fortalecimiento de la comprensión de lectura por medio de un ambiente de aprendizaje basado en la interpretación de infografías. (Tesis de maestría). Universidad de la Sabana, Chía, Colombia.

Pineda, J. (2011). Textos "links" vínculos, encajes, ligas y transtextos discontinuos. Una experiencia pedagógica. Encuentros, (1), 129-142. Recuperado de http://www.redalyc.org/articulo.oa?id=476655975010 
Reyes, P. y Mendoza, D. (2013). Comprensión e interpretación del texto narrativo libro álbum: voces que convocan a la armonía de sonidos en las narraciones familiares y escolares. (Tesis de pregrado) Universidad de Antioquia, Medellín, Colombia.

Rojas, R. (2013). El sentido del viaje de regreso a Ítaca: una propuesta para interpretar, desde una perspectiva semiótica, los textos de la literatura española renacentista y barroca en la enseñanza media. (Tesis de pregrado). Universidad de Antioquia, Medellín, Colombia.

Salazar, M. y Jaramillo, L. (2017) Cómo aprender a narrar a partir de la comprensión e interpretación de textos e imágenes-históricos de la edad media. (Tesis de maestría). Universidad Autónoma de Manizales, Manizales, Colombia.

Solé, I. (1987). Las posibilidades de un modelo teórico para la enseñanza de la comprensión lectora. Infancia y Aprendizaje: Journal for the Study of Education and Development, (39-40), 1-13. 